\title{
EVALUATION OF GROWTH OF SOME FUNGI IN CRUDE OIL POLLUTED ENVIRONMENT
}

\author{
C. I. ONUOHA, A. E. ARINZE and A. E. ATAGA \\ (Received 6 June 2002; Revision accepted 20 February 2003)
}

\begin{abstract}
The vegetative growth response of some fungi to different concentrations of crude oil was investigated. The result showed a variable degree of sensitivity to crude oil. The radial growth of Rhizopus sp. was not affected by the oil irrespective of the concentration. The two species of Aspergillus A. niger and A. flavus used in the study appreciably tolerated the oil though the growth of $A$. flavus was retarded as the concentration of oil increased. Botrytis cinerea, Curvularia lunata and Colletotrichum sp. could not grow beyond the concentration of $1 \mathrm{ml} / 10 \mathrm{~m} / \mathrm{s}$ of oil in Potato Dextrose Agar (PDA). The three fungi could serve as sensitivity index for monitoring oil pollution in an environment.
\end{abstract}

KEYWORDS: Crude oil, pollution, fungal growth.

\section{INTRODUCTION}

The existence of pollutants in the environment is a world wide problem. In the Nigerian environment, the major pollutant in recent times is crude oil resulting from the frequent oil spillages in the country (Awobajo 1981). Between 1970 and 1982 Nigeria recorded a total number of 1581 oil spill incidences according to the Nigerian National Petroleum Corporation (NNPC) and those spillages resulted to the loss of about 16 million barrels of crude oil. Most of the terrestrial ecosystem and shorelines in oil producing communities are important agricultural land under continuous cultivation. Any contact with crucle oil may result in damage to soil condition of these agricultural lands, (Plice, 1948: Rowell, 1977) microorganism, (Odu, 1972: Atlas and Bartha 1979), and plants (Baker, 1970). Beyond 3\% concentration in an environment, crude oil becomes increasingly deleterious to soil biota and crop growth (Schwendinger, 1968).

Although the toxicity of crude oil on plant (Baker, 1970, Amakiri and Onofeghara, 1984) and soil microflora, (Odu, 1972: Udo and Fayemi, 1975), have been investigated, the sensitivity of some specific common fungi in the Nigerian environment to crude oil pollution have not been exhausted.

This paper is therefore, aimed at testing the effects of crude oil on the vegetative growth of some of the common fungi within the Nigerian environment.

\section{MATERIALS AND METHODS}

\section{Source of Materials}

The crude oil (Bonny Light) used for the study was obtained from Port Harcourt Refinery Company (PHRC) Alesa Eleme and transported to plant Pathology laboratory of the University of Port Harcourt.

The fungi Aspergillus spp., Rhizopus sp., Curvularia lunata, Botrytis sp., Colletotrichum sp. and Fusarium sp. were isolated from the seeds of Okro (Abelmoschus esculentus L. Moench) and grains of maize (Zea mays L.).

\section{METHODS}

\section{Preparation of potato dextrose agar}

Two hundred grammes of peeled and sliced potato was boiled until soft. It was strained through muslin cloth and then made up to one litre with distilled water. Fifteen grammes of agar and $10 \mathrm{~g}$ of glucose were added. The mixture was boiled in water to melt the agar. It was autoclaved at $121^{\circ} \mathrm{C}$ for 15 minutes, poured into $500 \mathrm{ml}$ Erlenmayer's conical flask, stoppered and wrapped with alluminium foil.

Ten mililitres of PDA was dispensed into each of six sterile Petri-dishes. Crude oil was added to the liquid PDA in the following sequence: $0.5,1.0,1,5,2.0$, and $2.5 \mathrm{mls}$ using sterile syringe. This was repeated for each of the seven fungi. The mixture was vigorously shaken to obtain a uniform distribution of the oil and then allowed to solidify.

\section{Inoculation of the fungi}

The isolated fungi Curvularia lunata, Colletotrichum sp. Fusarium sp. Rhizopus sp., Aspergillus niger, Aspergillus flavus and Botrytis cinerea were inoculated into the different concentration of PDA/crude oil mixture. Three replicates were prepared for each fungus. A control that contained only PDA was also set up. All the inoculated Petri-dishes were incubated at a temperature of $25 \pm 2^{\circ} \mathrm{C}$ for seven days. Data were collected by measuring the diameter of growth of the fungi from the centre using a transparent plastic ruler.

\section{RESULTS}

In the Petri-dishes that contained no crude oil $C$. lunata, Collectotrichum sp and Botrytis cinerea covered 3.2, 2.4 and $1.8 \mathrm{~cm}$ respectively within seven days while $A$. niger, $R$ hizopus sp, A. flavus and Fusarium sp covered $4.5,4.5,4.5$ and $4.4 \mathrm{~cm}$ respectively. As the concentration of crude oil increased, the radial growth of the fungi decreased except in Rhizopus sp where the radial growth was not affected by crude oil as it maintained the same diameter irrespective of the concentration of the crude oil. The other fungi- $A$. niger, $A$ flavus, Fusarium sp., Curvularia lunata and Colletotrichum sp showed varied degrees of tolerance. The degree of reduction of the vegetative growth varied from one fungus to another, for instance Curvularia lunata did not grow beyond 0.5 


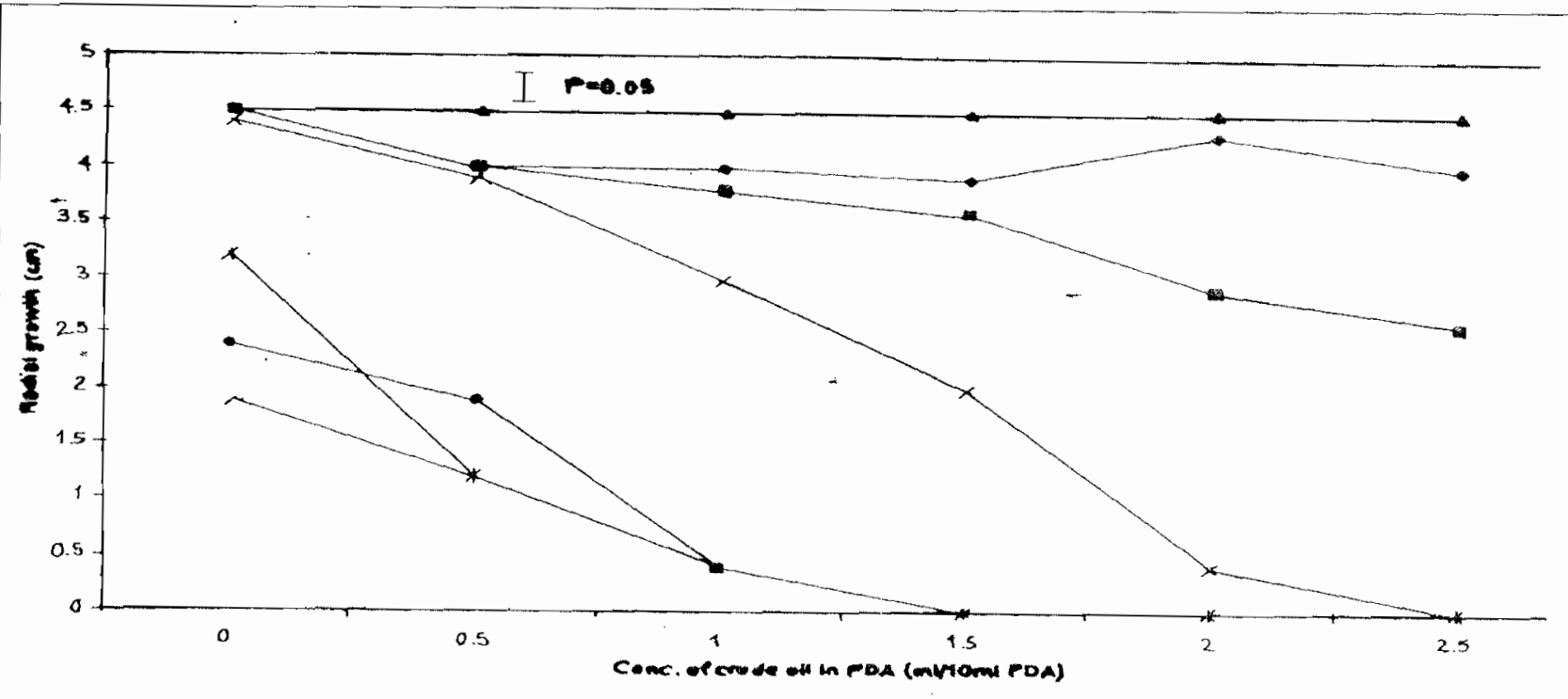

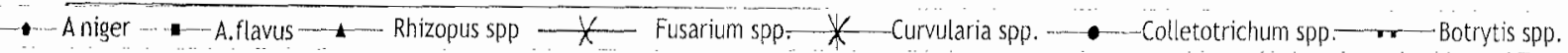

Fig 1. Efects of varying loads of Crude oil on the growth of the isolated fungi

mU 10ml crude oil/ PDA mixture while Aspergillus spp and Fusaruim sp continued growing up to $2.5 \mathrm{ml}$ concentration of crude oil. The result on vegetative growth of the fungi in crude oil/PDA mixture is summarised in figure 1.

\section{DISCUSSION}

The radial growth of Rhizopus sp was apparently independent of crude oil concentration in the medium. This is explicable in term of its (Rhizopus) ability to grow on all materials tike leather cloths and even organic liquids. Rhizopus has been described as a laboratory contaminant (Alexopoulos and Mims, 1979) and has been known to be ubiquitous.

Aspergillus spp were observed to be less tolerant to crude oil. Of the two species of this fungus used in the study $A$. niger was more aggressive in utilizing oil hydrocarbons than $A$. flavus. This implies that even within the same genus, the ability to utilize crude oil or other materials varies among the species. This may not be unconnected with the type of enzymes the organisms produce.

Curvularia lunata, Collectotrichum sp and Botrytis cinerea, however, were sensitive to the toxic effects of crude oil. This observation is in agreement with those of Petersen et.al (1991) and Venosa et.al. (1992) who independently reported that some hydrocarbons inhibit or retard metabolic pathways of oil degraders. This may be due to the presence of volatile compounds in crude oil which disturb metabolic pathways of micro-organisms. Survivors are those that have adapted to the environmental conditions through long periods of exposure leading to the evolution of the necessary enzymes. Certain microbes are killed in the presence of oil while the heterotrophic oil degraders survive (Siobhan and Edward, 1999).

From the present study, it was observed that various fungi isolated from seeds and grains of crops showed, to varying degrees, the ability to grow vegetatively in the presence of crude oil. The three fungi that could not grow beyond $0.5 \mathrm{ml} / 10 \mathrm{ml}$ concentration of crude oil, PDA mixture. Botrytis cinerea, Curvularia lunta and Colletotrichum sp could be used as sensitivity indices for monitoring oil spillages in the environment.

\section{REFERENCES}

Alexopoulos, C.J. and Mims, C. W., 1979. Introductory Mycology $3^{\text {rd }}$ John Wiley and Sons, New York. 632pp.

Amakiri, J.O. and Onofeghara, F.A., 1984. Effects of crude oil pollution on the germination of Zea mays and Capsicum frutescens. Environ. Pollut. 35:159 167.

Atlas, R. M and Bartha, R., 1979. Simulated Biodegradation of oil sticks using Oleophili fertilization. Environmental Sci. Technol. 7:538 541 .

Awobajo, 5. A., 1981. An analysis of oil spill, incidents in Nigeria (1976 1980) In: Proc. Of the 1981 International Seminar on Petroleum industry and the Nigerian Environment. NNPC Lagos 104109.

Baker; J.M., 1970. The Effects of oil on plants. Environ. Pollut. 1: 2730 .

Odu, C.T.I., 1972. Microbiology of soil contaminated with petroleum hydrocarbons, Extent of contamination and minobial properties after contamination. J. Inst of Petroleum 58: 201208.

Petersen, S.P, Kruse, B. and Jenson, K., 1991. Degradation of low toxicity drilling mud based oil in sediment cores. Mar. Pollut., Bull 22(9): 4245.

Plice, M. J., 1948. Some effects of crude petroleum on soil fertility. Soil Sci. Amer. Pro. 13: 412416.

Rowell, M. J., 1977. The effects of crude oil spills on soil: A review of Literature In: The reclamation of Agric soil after oil spill. Part I: Research (J. A. Toogood ed)AlP pub. 121pp.

Schwendinger, R. B. 1968. Reclamation of soil contaminated with oil. J. Inst. Pot 54:182 197.

Siobhan, B. M. and Edward, E. A., 1999. Anaerobic Benzene Biodegradation Linked to nitrate reduction. Appl. Environ. Microbi. $65(2): 529533$.

Udo, E. J. and Fayemi, A. A., 1975. The effects of soil pollution on germination, growth and nutrient uptake of corn. J. Environ Qual. 4:437 440 .

Venasa, A.D., Haines, J.R., Nisamaneepong, N., Govind, R., Pradhan and Siddiques, 1992. Efficiency of Commercial Products in enhancing oil Biodegradation in closed laboratory Reactors. J. Ind. Microbiol. 10(1):13 23. 